\title{
Hydrogen ameliorates pulmonary hypertension in rats by anti-inflammatory and antioxidant effects
}

\author{
Yasuaki Kishimoto, MD, ${ }^{a}$ Taichi Kato, $\mathrm{MD}, \mathrm{PhD},{ }^{\mathrm{a}}$ Mikako Ito, $\mathrm{PhD},{ }^{\mathrm{b}}$ Yoshiteru Azuma, MD, a,b \\ Yoshie Fukasawa, MD, ${ }^{\mathrm{a}}$ Kinji Ohno, $\mathrm{MD}, \mathrm{PhD},{ }^{\mathrm{b}}$ and Seiji Kojima, MD, $\mathrm{PhD}^{\mathrm{a}}$
}

\begin{abstract}
Objective: The pathogenesis of pulmonary arterial hypertension $(\mathrm{PAH})$ involves reactive oxygen species and inflammation. Beneficial effects of molecular hydrogen, which exerts both anti-inflammatory and antioxidative effects, have been reported for various pathologic conditions. We therefore hypothesized that molecular hydrogen would improve monocrotaline (MCT)-induced PAH in rats.
\end{abstract}

Methods: Nineteen male Sprague-Dawley rats (body weight: 200-300 g) were divided into groups, receiving: (1) MCT + hydrogen-saturated water (group $\mathrm{H})$; (2) MCT + dehydrogenized water (group M); or (3) saline + dehydrogenized water (group C). Sixteen days after substance administration, we evaluated hemodynamics, harvested the lungs and heart, and performed morphometric analysis of the pulmonary vasculature. Macrophage infiltration, antiproliferating cell nuclear antigen-positive cells, 8-hydroxy-deoxyguanosine (8-OHdG)positive cells, and expressions of phosphorylated signal transducers and activators of transcription-3 (STAT3) and nuclear factor of activated T-cells (NFAT) were evaluated immunohistochemically. Stromal cell-derived factor-1 and monocyte chemoattractant protein-1 expressions were evaluated by quantitative reversetranscription polymerase chain reaction.

Results: Pulmonary arterial hypertension was significantly exacerbated in group M compared to group $\mathrm{C}$, but was significantly improved in group $\mathrm{H}$. Vascular density was significantly reduced in group $\mathrm{M}$, but not in group $\mathrm{H}$. Adventitial macrophages, antiproliferating cell nuclear antigen - and 8-OHdG-positive cells, and stromal cell-derived factor-1 and monocyte chemoattractant protein-1 expressions were significantly increased in group $\mathrm{M}$, but improved in group $\mathrm{H}$. Expressions of phosphorylated STAT3 and NFAT were up-regulated in group $\mathrm{M}$, but improved in group $\mathrm{H}$.

Conclusions: Molecular hydrogen ameliorates MCT-induced PAH in rats by suppressing macrophage accumulation, reducing oxidative stress and modulating the STAT3/NFAT axis. (J Thorac Cardiovasc Surg 2015;150:645-54)

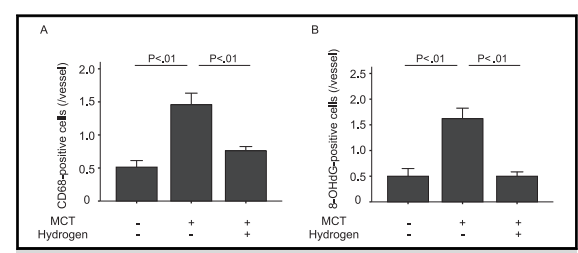

Molecular hydrogen reduces CD68- and 8-OHdGpositive cells. A, CD68-positive cells, and (B) 8-OHdG-positive cells in adventitia were increased by MCT, but decreased by hydrogen.

Central Message

This study demonstrated that molecular hydrogen ameliorates MCT-induced pulmonary hypertension in rats by suppressing macrophage accumulation, reducing oxidative stress and modulating the STAT3/NFAT axis.

\section{Perspective}

This study demonstrated that molecular hydrogen ameliorates monocrotaline-induced PAH in rats by suppressing inflammation and reducing oxidative stress. Considering antiinflammatory and anti-oxidative effect, molecular hydrogen may be applicable for the patients with idiopathic PAH, PAH associated with connective tissue disease or with infection, or patients with $\mathrm{PAH}$ on cardio-pulmonary bypass.

See Editorial Commentary page 654

\section{Supplemental material is available online.}

Pulmonary arterial hypertension (PAH) is a rare, but life-threatening, disease characterized by proliferation of vascular wall cells and remodeling of precapillary arteries,

\footnotetext{
From the ${ }^{\mathrm{a}}$ Department of Pediatrics; and ${ }^{\mathrm{b}}$ Division of Neurogenetics, Center for Neurological Diseases and Cancer, Nagoya University Graduate School of Medicine, Nagoya, Japan.

This work was supported by JSPS KAKENHI Grant Number 21790981

Received for publication Dec 6, 2014; revisions received May 13, 2015; accepted for publication May 17, 2015; available ahead of print June 19, 2015.
}

resulting in the elevation of pulmonary arterial pressure, and right ventricular failure. Current therapies, including the use of prostanoids, endothelin receptor antagonists, and phosphodiesterase-5 inhibitors, have improved the prognosis for patients with $\mathrm{PAH}$, but morbidity and mortality rates remain high. ${ }^{1,2}$ Novel approaches based on the underlying pathophysiology must therefore be developed to improve PAH treatment. 


\section{Abbreviations and Acronyms \\ $\mathrm{MCT}=$ monocrotaline \\ NFAT = nuclear factor of activated T-cells \\ PAH = pulmonary arterial hypertension \\ STAT3 = signal transducers and activators of transcription-3 \\ TGFBR $=$ transforming growth factor beta receptor 8-OHdG $=8$-hydroxy-deoxyguanosine}

The pathogenesis of PAH involves reactive oxygen species $^{3}$ and inflammation. ${ }^{4}$ Reactive oxygen species induce hypertrophy and muscularization of the vessel media, and contraction of pulmonary arteries, resulting in the development and progression of $\mathrm{PAH} .{ }^{3}$ Inflammation leads to the recruitment of macrophages to the vascular lesion, followed by pulmonary artery medial hypertrophy and vascular remodeling. ${ }^{4}$ Among subgroups of PAH, inflammation plays an important role, particularly in PAH that is idiopathic, associated with connective tissue disease, associated with infection, or an experimental model, such as monocrotaline (MCT)-induced PAH.

Molecular hydrogen has been reported to show both anti-inflammatory and antioxidative activity, and to modulate signaling. Beneficial effects of molecular hydrogen have been reported recently for various pathologic conditions, including a rat model of ischemia and reperfusion brain injury, and a rat model of Parkinson's disease. ${ }^{5,6}$ Although therapeutic effects of molecular hydrogen have been evaluated in various disease models, the role of hydrogen in the treatment of PAH has not been fully established.

The signal transducers and activators of transcription-3 (STAT3)/nuclear factor of activated T-cells (NFAT) axis is known to regulate diverse cellular processes, including growth and survival. ${ }^{8}$ This axis promotes the proliferation of smooth muscle cells, and leads to the development and progression of $\mathrm{PAH}$. Moreover, superoxide activates NFAT in pulmonary arteries of the superoxide dismutase 1-knockout mouse. ${ }^{9}$ We therefore tested the hypothesis that molecular hydrogen would decrease MCT-induced PAH in rats, by modulating the STAT3/NFAT axis through anti-inflammatory and antioxidative effects.

\section{METHODS}

\section{Animal Models}

All rat experiments were approved by the Animal Care and Use Committee of the Nagoya University Graduate School of Medicine. All rats received humane care according to the Regulations on Animal Experiments at Nagoya University. Male Sprague-Dawley rats, aged 7 weeks (Charles River Laboratories Japan, Kanagawa, Japan) were divided into 3 groups: group $\mathrm{H}$, which received $\mathrm{MCT}+$ hydrogen-saturated water $(n=6)$; group M, which received MCT + dehydrogenized water $(n=7)$; and group $C$, which received saline + dehydrogenized water $(n=6)$.
Rats were administered either a single dose of $60 \mathrm{mg} / \mathrm{kg}$ body weight of MCT (Wako Pure Chemical Industries, Ltd, Osaka, Japan) dissolved in phosphate-buffered saline subcutaneously to induce $\mathrm{PAH}$, or the same volume of saline, as described elsewhere. ${ }^{10}$ Hydrogen-saturated water or dehydrogenized water was supplied on days -7 to 16 , from before to after the administration of MCT or saline. Hydrogen-saturated water (1.6 ppm or $0.8 \mathrm{mM}$ ) was prepared daily, using an AquelaBlue electrolysis instrument (Miz Co Ltd, Fujisawa, Japan). ${ }^{11}$ Rats were housed ad libitum to food and water, including hydrogen-saturated water in group $\mathrm{H}$, under a natural day/night cycle. Rats were acclimated for 7 days before any experimental procedures were conducted.

\section{Hemodynamic Studies and Evaluation of Right Ventricular Hypertrophy}

Animals were killed as previously described, ${ }^{10}$ with administration of pentobarbital sodium $(45 \mathrm{mg} / \mathrm{kg}$ ). Right ventricular systolic pressure was measured $^{12}$ percutaneously by insertion of a 22 -gauge needle connected to a pressure transducer and an amplifier system (LEG-1000; Nihon Kohden Co, Tokyo, Japan). We maintained the ventilation of animal lungs using a rodent respirator (SAR-830 small animal ventilator; CWE Inc, Ardmore, $\mathrm{Pa}$ ) while harvesting the lungs and heart. Right ventricular hypertrophy was estimated by measuring the ratio: [right ventricular free wall weight $] /[$ left ventricular free wall plus interventricular septum weight $] .{ }^{13}$

\section{Pulmonary Arterial Morphometry and Immunohistochemistry}

We performed histopathologic observations as reported elsewhere. ${ }^{13}$ Briefly, specimens of the left lung were harvested and flushed with phosphate-buffered saline, followed by fixation with $4 \%$ paraformaldehyde (Wako Pure Chemical Industries, Ltd) in phosphate-buffered saline, at $4{ }^{\circ} \mathrm{C}$, for 3 hours, followed by $30 \%$ sucrose in phosphate-buffered saline, at $4^{\circ} \mathrm{C}$, overnight, and embedded in paraffin or Tissue-Tek OCT (optimum cutting temperature) compound (Sakura Finetek Japan, Tokyo, Japan). Paraffin sections of lung (thickness: $4 \mu \mathrm{m}$ ) were blocked first with $3 \%$ hydrogen peroxide for endogenous peroxidases, followed by $5 \%$ swine serum in phosphate-buffered saline, followed by incubation with primary antibody. Sections were washed in phosphate-buffered saline, and antibody binding was determined using an LSAB + System-HRP kit or LSAB+ System-AP kit (Dako, Carpinteria, Calif). After extensive washing, sections were counterstained with hematoxylin (Dako) and visualized under light microscopy (IX71; Olympus, Tokyo, Japan).

For double immunofluorescence staining, frozen sections of lung (thickness: $5 \mu \mathrm{m}$ ) were blocked with $5 \%$ donkey serum in phosphatebuffered saline, followed by incubation with primary antibody and visualization with Alexa 594 or 488-conjugated donkey antirabbit or antimouse immunoglobulin (Ig)G (Life Technologies, Gaithersburg, Md), or a Zenon Alexa Fluor Labeling Kit (Life Technologies). All sections were counterstained with TOPRO-3 (Life Technologies), mounted with fluorescent mounting medium (Dako) and visualized under confocal microscopy (A1R; Nikon, Tokyo, Japan).

Primary antibodies were: anti- $\alpha$-smooth muscle mouse monoclonal antibody (dilution 1:1000, clone 1A4; Sigma-Aldrich, St Louis, Mo); antiproliferating cell nuclear antigen mouse monoclonal antibody (dilution 1:1000, clone PC10; Abcam, Cambridge, United Kingdom); anti-CD68 mouse monoclonal antibody (dilution 1:200, clone ED1; Abcam); anti-8-hydroxy-deoxyguanosine (8-OHdG) mouse monoclonal antibody (dilution 1:100, clone N45.1; Japan Institute for the Control of Aging [JaICA], Shizuoka, Japan); anti-NFAT1 mouse monoclonal antibody (dilution 1:100, clone 25A10.D6.D2; Abcam); and anti-phospho-STAT3 (Tyr705) XP rabbit monoclonal antibody (dilution 1:200, clone D3A7; Cell Signaling Technology, Denver, Colo).

For muscularization of pulmonary arterial media, anti- $\alpha$-smooth muscle antibody-stained sections were evaluated in a blinded manner, as described 
elsewhere. ${ }^{10}$ Briefly, pulmonary arterioles, with an external diameter of 50 to $100 \mu \mathrm{m}$, in 40 independent high-power fields, were classified by circumferential staining with anti- $\alpha$-smooth muscle antibody as: nonmuscular arteries $(<25 \%)$; partially muscular arteries $(25 \%-75 \%)$; or muscular arteries $(>75 \%)$, in a blinded manner. The percentage of muscular arteries per total number of pulmonary arteries was determined.

Vascular density was assessed as reported elsewhere. ${ }^{14}$ Briefly, on Elastica van Gieson staining, the number of vessels $(25-100 \mu \mathrm{m}$ in diameter) per 100 alveoli was quantified in 20 independent fields per lung, at a $\times 100$ magnification, in a blinded manner. Fields containing large airways or major pulmonary vessels were avoided, to maintain the consistency of counts between sections.

\section{Quantitative Reverse-Transcription Polymerase Chain Reaction}

Ribonucleic acid was isolated after homogenization of snap-frozen lungs, using the RNeasy Mini Kit (Qiagen, Hilden, Germany). Ribonucleic acid was reverse-transcribed using a SuperScript VILO cDNA Synthesis Kit (Invitrogen, Carlsbad, Calif). We performed quantitative reverse-transcription polymerase chain reaction, using SYBR Green (Brilliant III Ultra-Fast SYBR Green; Agilent Technologies Inc, Santa Clara, Calif) and the Mx3005P Realtime qPCR System (Agilent Technologies, Inc). Expressions of stromal cell-derived factor-1, monocyte chemoattractant protein-1, bone morphogenetic protein receptor-2, transforming growth factor beta receptor (TGFBR)1, TGFBR2, TGFBR3, Smad2, Smad3, and Smad4 were normalized to glyceraldehyde 3-phosphate dehydrogenase as the product of a housekeeping gene. Forward and reverse primers are shown in Table E1.

\section{Statistical Analysis}

Values are presented as the mean with standard error. All data were statistically analyzed using SPSS, version 21 (SPSS, Inc, Chicago, Ill). Statistical comparisons among 3 groups were performed by 1-way analysis of variance followed by the Bonferroni post hoc test. Values of $P<.05$ after Bonferroni correction $(P<.017$ before Bonferroni correction) were considered statistically significant.

\section{RESULTS}

\section{Hydrogen-Saturated Water Treatment Improved MCT-Induced Pulmonary Hypertension}

Right ventricular systolic pressure was significantly elevated in group $\mathrm{M}(62.43 \pm 4.77 \mathrm{~mm} \mathrm{Hg})$ compared with group $\mathrm{C}(23.67 \pm 3.16 \mathrm{~mm} \mathrm{Hg}, P<.01)$, but it was significantly improved in group $\mathrm{H}(39.83 \pm 1.89 \mathrm{~mm} \mathrm{Hg}$, $P<.01$ vs group M) (Figure $1, A$ ). Similarly, the ratio of right ventricular free wall weight to left ventricular free wall plus interventricular septum weight increased in group $\mathrm{M}(0.47 \pm 0.03)$, compared with group $\mathrm{C}(0.27 \pm 0.01$, $P<.01)$, and was significantly resolved in group $\mathrm{H}$ $(0.34 \pm 0.01, P<.01$ vs group M) (Figure $1, B)$. The percentage of muscularized pulmonary artery was significantly augmented in group $\mathrm{M}(50.7 \% \pm 6.1 \%)$, compared with group C $(23.8 \% \pm 7.2 \%, P=.013)$, and was significantly reduced in group $\mathrm{H}(14.3 \% \pm 2.9 \%, P<.01$ vs group $\mathrm{M})$ (Figure 1,C). Hematoxylin and eosin staining, Elastica van Gieson staining, and immunohistochemistry with anti- $\alpha$-smooth muscle antibody confirmed that the pulmonary arterial medium was hypertrophied in group $\mathrm{M}$, and the change was ameliorated in group $\mathrm{H}$ (Figure 1, D-L). No mortality occurred within 16 days, in either group.

\section{Hydrogen-Saturated Water Treatment Reduced Smooth Muscle Cell Proliferation and Increased Vascular Density}

The percentage of antiproliferating cell nuclear antigen-positive cells among the total number of pulmonary artery smooth muscle cells was significantly increased in group $\mathrm{M}(0.23 \% \pm 0.01 \%)$, compared with group C $(0.09 \% \pm 0.01 \%, P<.01)$, and it was significantly improved in group $\mathrm{H}(0.09 \% \pm 0.01 \%, P<.01$ vs group $\mathrm{M})$ (Figure 1, $M$ ). On the other hand, vascular density, which was calculated as the numbers of vessels per 100 alveoli, was significantly reduced in group $\mathrm{M}(4.06 \pm 0.14)$, compared with group $\mathrm{C}(6.00 \pm 0.16, P<.01)$, but it was improved in group $\mathrm{H}(5.18 \pm 0.24, P<.01$ vs group $\mathrm{M})$ (Figure $1, N)$.

\section{Hydrogen-Saturated Water Treatment Reduced Inflammation and Oxidative Stress}

Adventitial macrophages per vessel were increased in group $\mathrm{M}(1.46 \pm 0.18)$, compared with group $\mathrm{C}$ $(0.51 \pm 0.10, P<.01)$, but counts were largely normalized in group $\mathrm{H}(0.76 \pm 0.07, P<.01$ vs group $\mathrm{M})$ by hydrogensaturated water. Adventitial $8-\mathrm{OHdG}$-positive cells per vessel were elevated in group $\mathrm{M}(1.62 \pm 0.19)$, compared with group $\mathrm{C}(0.50 \pm 0.14, P<.01)$, and were normalized in group $\mathrm{H}(0.50 \pm 0.08, P<.01$ vs group $\mathrm{M})$. Furthermore, 8-OHdG was coexpressed in adventitial CD68-positive cells (Figure 2; Figure E1). On the other hand, stromal cell-derived factor-1 and monocyte chemoattractant protein-1 expressions, as evaluated by quantitative reverse-transcription polymerase chain reaction, were increased in group $\mathrm{M}(6.2 \pm 0.8$-fold, $P<.01$; $37.7 \pm 13.7$-fold, $P=.012$, respectively), but decreased in group $\mathrm{H}(1.5 \pm 0.2$-fold, $P<.01 ; 5.4 \pm 1.9$-fold, $P=.029$, respectively) (Figure 3, $A$ and $B$ ). Furthermore, bone morphogenetic protein receptor type 2 expression was decreased in group $\mathrm{M}(0.46 \pm 0.06$-fold, $P=.046)$, and slightly restored in group $\mathrm{H}(0.58 \pm 0.07$-fold $)$ (Figure 3, C). TGFBR1, TGFBR2, TGFBR3, Smad2, Smad3, and Smad4 expressions showed no significant differences among the 3 groups (Figure E2).

\section{Hydrogen-Saturated Water Treatment Ameliorates PAH by Modulating the STAT3/NFAT Axis}

Expression of NFAT at smooth muscle cell was up-regulated in group $\mathrm{M}$, and down-regulated in group $\mathrm{H}$, compared with group M. Expression of phosphorylated STAT3 at smooth muscle cell was additionally up-regulated in group $\mathrm{M}$ and down-regulated in group $\mathrm{H}$, compared with group $M$ (Figure 4).

\section{DISCUSSION}

This study demonstrated that molecular hydrogen ameliorates MCT-induced pulmonary hypertension in rats. 


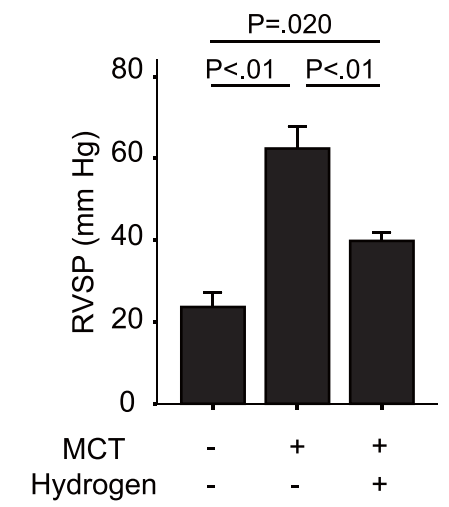

A

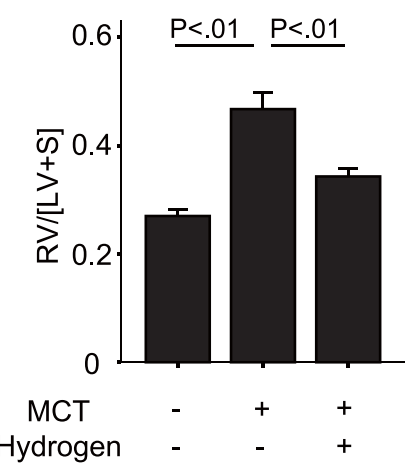

B

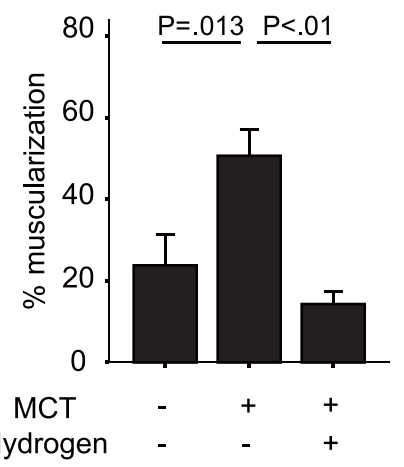

C
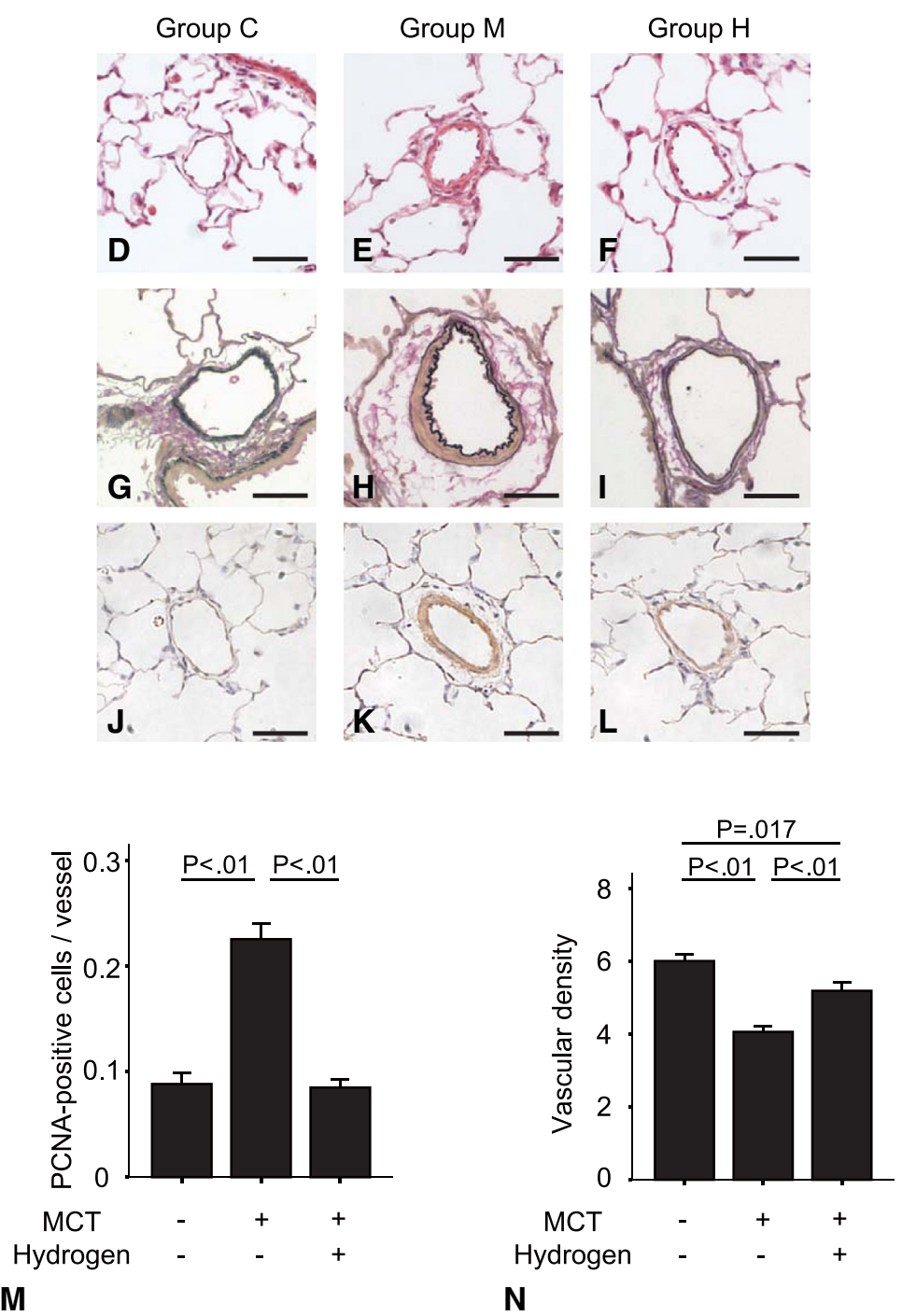

FIGURE 1. Molecular hydrogen improves MCT-induced pulmonary arterial hypertension. A, RVSP; (B) RV/[LV+S] weight ratio; and (C) the percentage of muscularized pulmonary artery were significantly elevated by MCT, but significantly improved by hydrogen. Medial hypertrophy in pulmonary arterial smooth muscle was exacerbated by MCT, but restored by hydrogen on (D-F) hematoxylin and eosin staining; (G-I) Elastica van Gieson staining; and (J-L) immunohistochemistry with anti- $\alpha$-smooth muscle antibody. Scale bar $=50 \mu \mathrm{m}$. Antiproliferating cell nuclear antigen-positive cells were significantly increased by MCT, but significantly decreased by hydrogen (M). Vascular density (vessels per 100 alveoli) was significantly reduced by MCT, but improved by molecular hydrogen $(\mathrm{N}) . R V S P$, Right ventricular systolic pressure; $R V$, right ventricle; $L V$, left ventricle; $S$, septum; $M C T$, monocrotaline; $P C N A$, proliferating cell nuclear antigen. 

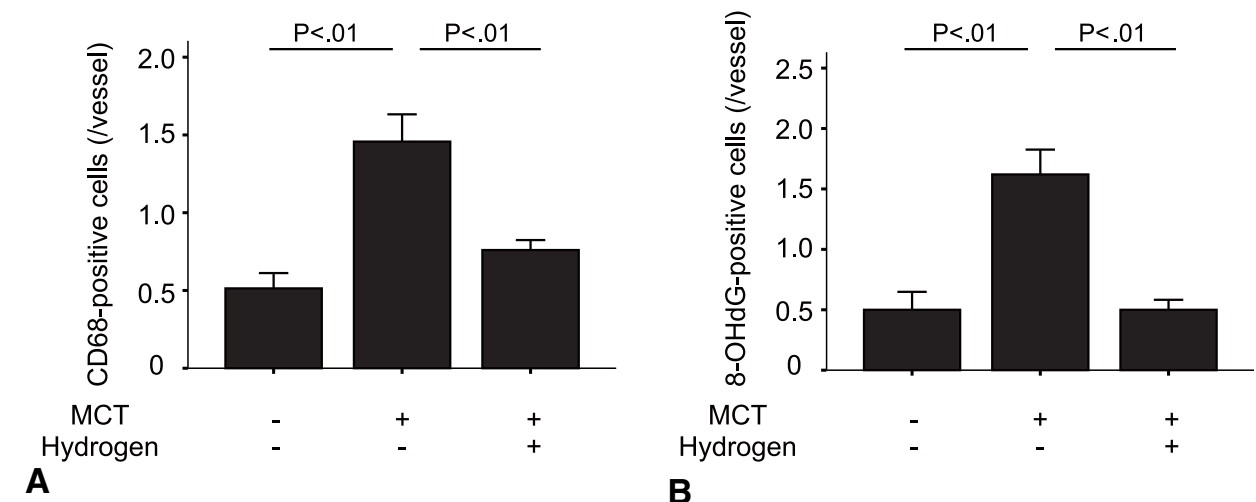

B
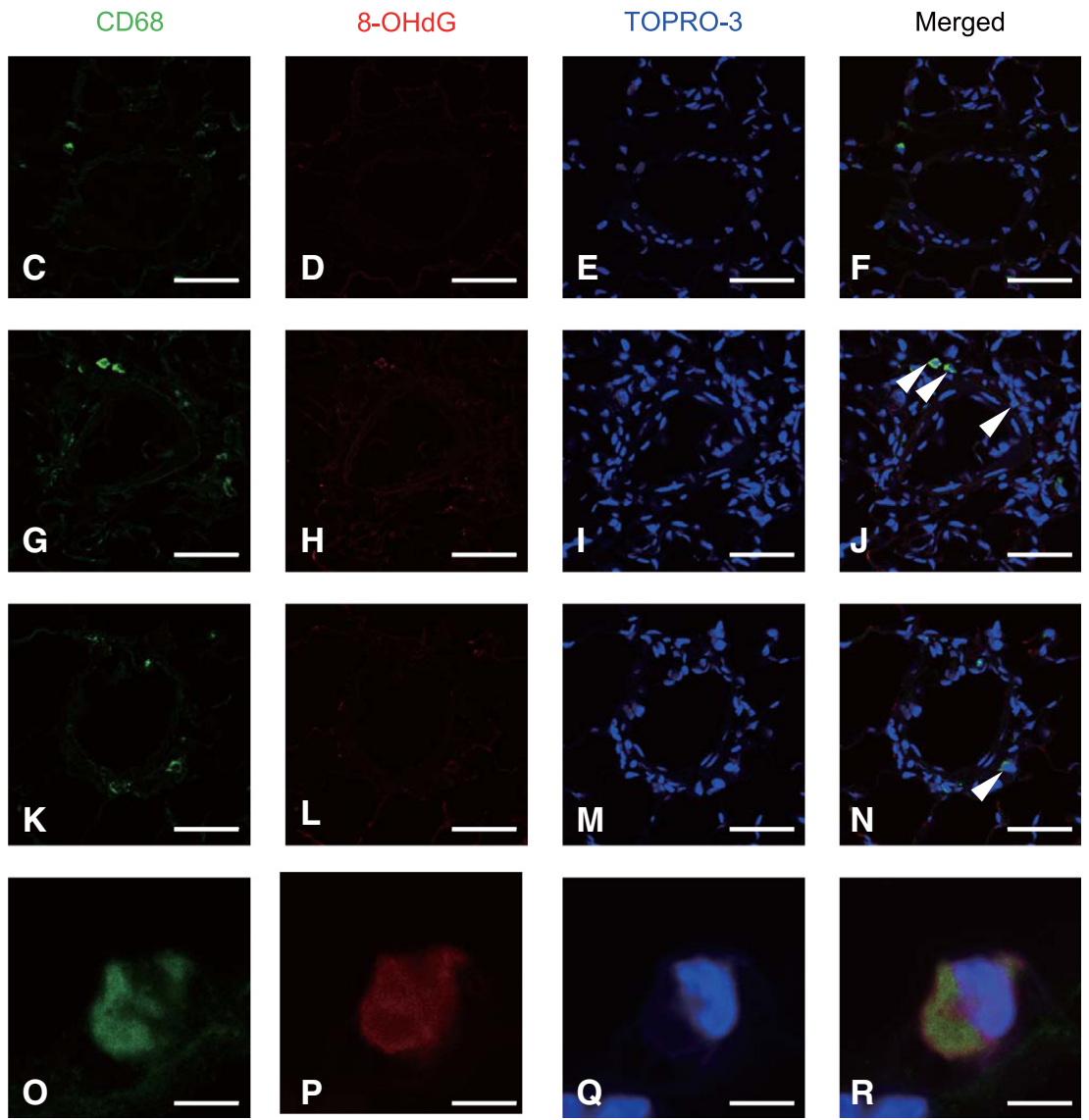

FIGURE 2. Molecular hydrogen reduces CD68- and 8-OHdG-positive cells. A, CD68-positive cells, and (B) 8-OHdG-positive cells in adventitia were increased by MCT, but decreased by hydrogen. Representative figures from immunofluorescence confocal microscopy are shown. Macrophages are labeled with CD68 (green); sites of oxidative stress are labeled with 8-OHdG (red), and the nucleus is labeled with TOPRO-3 (blue; Life Technologies). Arrowheads indicate CD68-positive and 8-OHdG-positive cells. C-F, Group C. G-J, Group M. K-N, Group H. Scale Bar $=50 \mu$ m. O-R, Coexpression of CD68 and 8-OHdG in adventitial cells in a high-power field is shown. Scale bar $=5 \mu \mathrm{m}$. MCT, Monocrotaline; 8 - $O H d G, 8$-hydroxydeoxyguanosine.

The major new findings of this investigation were that molecular hydrogen suppressed inflammation, reduced reactive oxygen species, and restored the injury to macrophages caused by oxidative stress. Second, molecular hydrogen modulated the STAT3/NFAT axis in inhibiting MCT-induced PAH in a rat model. Third, oral administration of molecular hydrogen in this time course was effective in the MCT-induced PAH rat.

This study showed that molecular hydrogen ameliorated $\mathrm{PAH}$, as demonstrated by improved right ventricular systolic pressure, a resolved weight ratio ([right ventricle free wall]/[left ventricle free wall + interventricular 

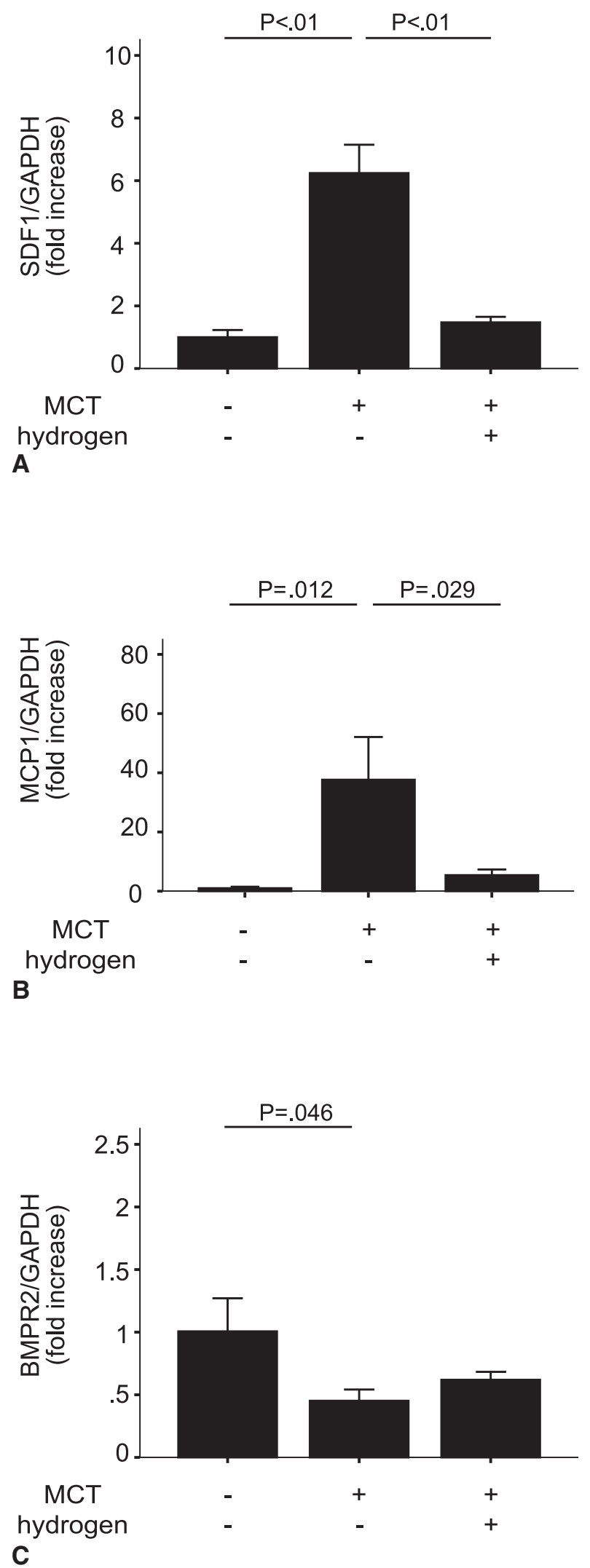

septum]), and a reduced percentage of muscularized pulmonary arteries (Figure 1, $A-L$ ). An increased weight ratio in group $\mathrm{M}$ suggested that compensatory hypertrophy of the right ventricle occurred during a 16-day period. In addition, our results indicate that molecular hydrogen inhibited smooth muscle cell proliferation and vascular remodeling (Figure 1, $M$ and $N$ ). Smooth muscle cell proliferation and vascular remodeling increase pulmonary arterial resistance, and lead to elevated right ventricular systolic pressure. These conditions are critical in the development and progression of PAH.

Because PAH develops $\geq 14$ days after MCT injection, we did not perform evaluations prior to 16 days after MCT injection. The PAH model rats were killed at 16 days after MCT injection. Given that all model rats survived to day 16 , analysis of the effects of hydrogen on survival was not performed.

Our findings showed that increased adventitial macrophages in MCT-induced PAH lesions were decreased by molecular hydrogen (Figure 2, A; Figure E1, $A-F$ ). Inflammation plays a key role in the development of PAH, particularly in several types of group $1 \mathrm{PAH}$ in the Nice classification. In patients with PAH, levels of circulating cytokines or C-reactive protein correlate with disease severity and outcome. ${ }^{15,16}$ In addition, in vascular lesions of PAH, infiltration of inflammatory cells, including macrophages, dendritic cells, $\mathrm{T}$ and $\mathrm{B}$ lymphocytes, and mast cells in perivascular spaces have been noted. ${ }^{17,18}$ Among these, increased recruitment of perivascular macrophages derived from bone marrow has been reported in MCT-induced PAH rats. ${ }^{19}$ Depletion of circulating mononuclear cells of a monocyte/macrophage lineage prevented pulmonary adventitial remodeling. ${ }^{20}$ In addition, among anti-inflammatory agents, dexamethasone ameliorates MCT-induced PAH in rats. ${ }^{21}$ In patients with systemic lupus erythematosus, treatment for the inflammatory condition resulted in improvement of PAH. ${ }^{22}$

Such results suggest that suppression of macrophages might offer a rational approach to inhibiting several types of PAH in which inflammation plays a key role. In line

FIGURE 3. Molecular hydrogen reduces SDF-1 and MCP-1 expression. A, SDF-1 and (B) MCP-1 expression, as evaluated by quantitative reverse-transcription polymerase chain reaction, were significantly up-regulated by MCT, but significantly suppressed by molecular hydrogen. C, BMPR2 expressions were decreased by MCT, but were not restored by molecular hydrogen. SDF, Stromal cell-derived factor-1; GAPDH, glyceraldehyde 3-phosphate dehydrogenase; $M C T$, monocrotaline; $M C P$, monocyte chemoattractant protein; $B M P R 2$, bone morphogenetic protein receptor type 2 . 
NFAT1
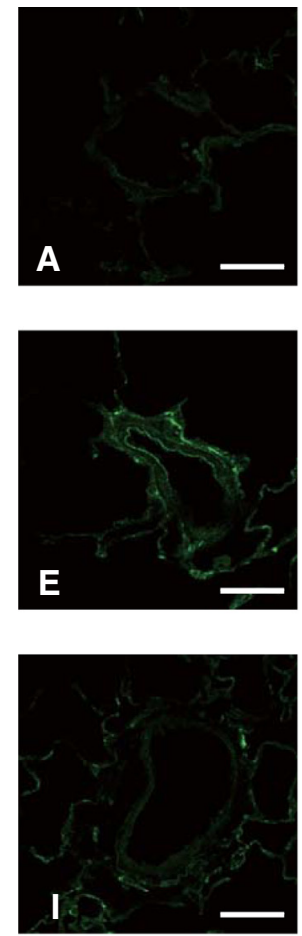

pSTAT3
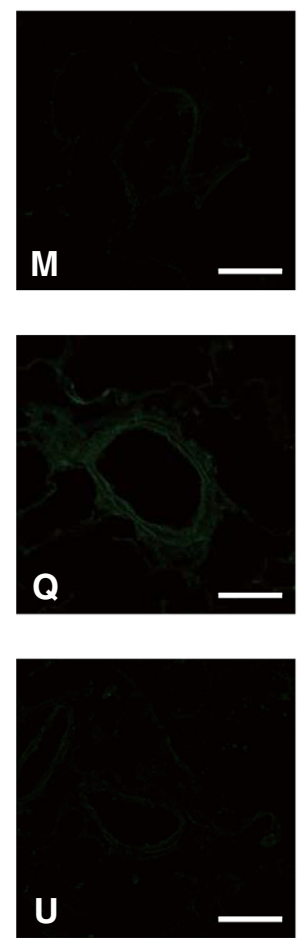

aSMA
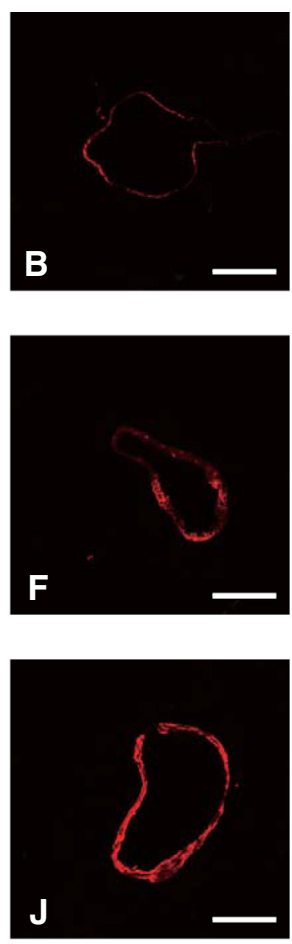

aSMA
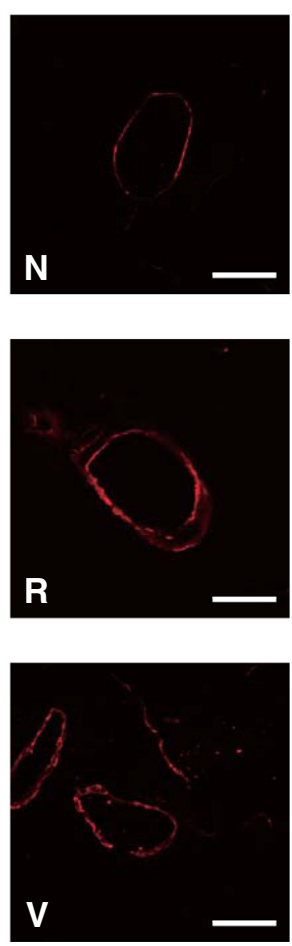

TOPRO-3
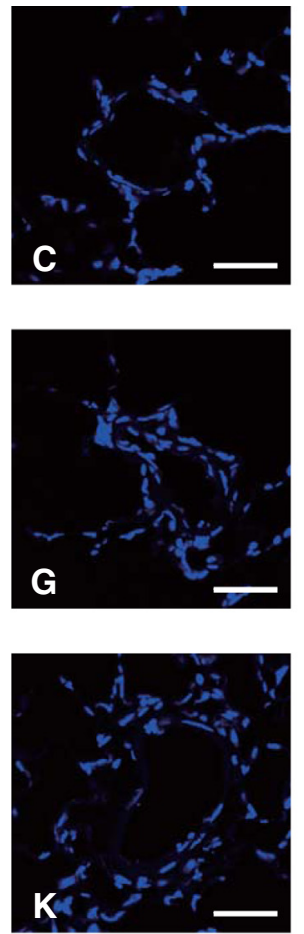

TOPRO-3
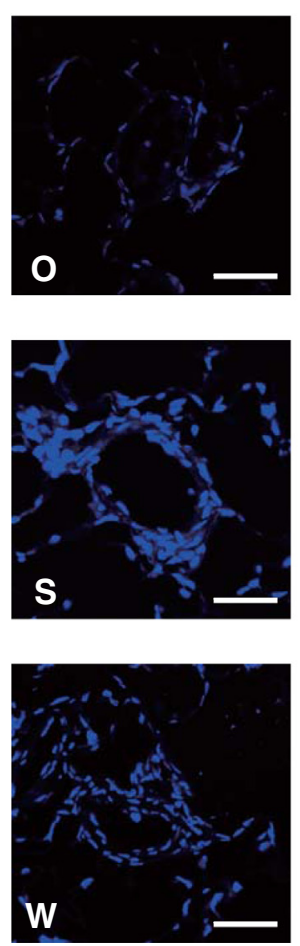

Merged
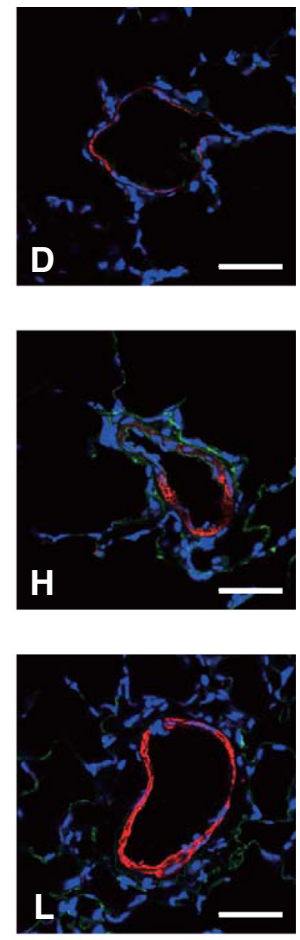

Merged
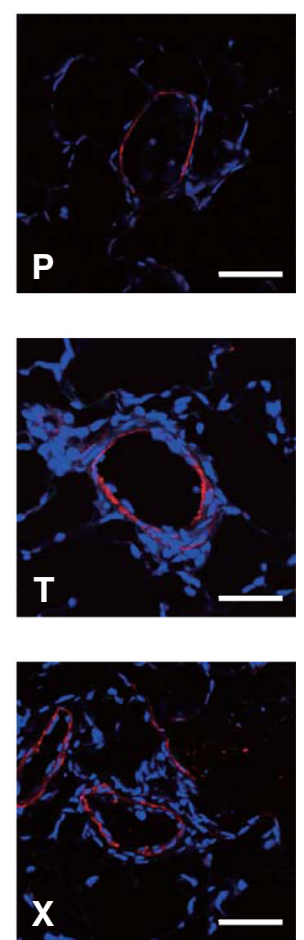

FIGURE 4. Molecular hydrogen ameliorates MCT-induced PAH, through modulation of the STAT3/NFAT axis. On immunostaining, expressions of NFAT1 ([A-D], group C; [E-H], group M; [I-L], group H) and phosphorylated STAT3 ([M-P], group C; [Q-T], group M; [U-X], group H) are up-regulated by MCT, and down-regulated by hydrogen ([A-D] and [M-P], group C; [E-H] and [Q-T], group M; [I-L] and [U-X], group H). Scale bar $=50 \mu \mathrm{m}$. NFAT, Nuclear factor of activated T-cells; SMA, smooth muscle actin; STAT3, signal transducers and activators of transcription-3. 
with the dynamics of macrophages in the adventitia, we found that expressions of monocyte chemoattractant protein-1 and stromal cell-derived factor- 1 in lung were up-regulated by MCT, and restored by molecular hydrogen (Figure 3, $A$ and $B$ ). Monocyte chemoattractant protein-1 and stromal cell-derived factor- 1 are known to be important molecules in attracting macrophages to disease sites. ${ }^{23,24}$ Moreover, monocyte chemoattractant protein-1 induces smooth muscle cell proliferation and vascular remodeling in pulmonary arterioles. ${ }^{25}$

In addition, reactive oxygen species play an important role in the pathogenesis of PAH. Bowers and colleagues ${ }^{26}$ demonstrated that 8-OHdG, a marker of deoxyribonucleic acid oxidation, was strongly expressed in: endothelial cells; poorly organized, incipient vascular channels of plexiform lesion; and perivascular macrophages in patients who had $\mathrm{PAH}^{26}$ In an animal model, Csiszar and colleagues ${ }^{27}$ showed that pulmonary hypertension in MCT-treated rats was associated with oxidative stress, as indicated by up-regulation of reduced nicotinamide adenine dinucleotide phosphate oxidase. ${ }^{27}$ Wang and colleagues ${ }^{28}$ demonstrated that hydrogen-rich saline ameliorated MCT-induced pulmonary hypertension with decreased malondialdehyde and 8-OHdG levels, and increased superoxide dismutase activity in the lung tissue and serum. ${ }^{28}$ However, so far, the activity of oxidative stress in the treatment of pulmonary hypertension by molecular hydrogen has not been fully studied with histologic evaluation. ${ }^{28,29}$ Our data show that molecular hydrogen reduced the level of 8-OHdG-positive macrophages (Figure 2, $B$-R; Figure E1, $G-I$ ).

Finally, we demonstrated that molecular hydrogen ameliorated PAH by inhibiting the activation of the STAT3/NFAT axis (Figure 4, $A-X$ ). As an important activator of $\mathrm{T}$ cells, NFAT increases the transcription of inflammatory mediators. Activation of NFAT in PAH leads to inflammatory vascular remodeling of the pulmonary arteries and proliferation of smooth muscle cells. ${ }^{30}$ In line with this observation, NFAT inhibitor prevented an increase in right ventricular systolic pressure, and decreased pulmonary arterial wall thickness in superoxide dismutase 1-knockout mice. ${ }^{9}$ STAT3 is a cytoplasmic transcription factor associated with cell growth and survival. A recent report described the STAT3/NFAT axis as up-regulated in both human PAH and rat MCT-induced PAH. ${ }^{8}$ A previous study reported that, in rats treated with ferric nitrilotriacetate as an oxidative stress model in renal tubular cells, molecular hydrogen suppressed ferric nitrilotriacetateinduced STAT3 phosphorylation. ${ }^{31}$ However, further study is needed to determine whether oxidative stress directly activated the STAT3/NFAT axis in our MCT-induced PAH model.

Vasoactive intestinal peptide is reported to attenuate MCT-induced PAH with inhibition of inflammation. ${ }^{32}$ In addition, an effect of vasoactive intestinal peptide has been suggested to result from inhibition of NFAT signaling, but this has not been fully elucidated. On the other hand, Courboulin and colleagues $^{33}$ reported that plumbagin ameliorated MCT-induced PAH by modulating the STAT3/NFAT axis. That study, and our own, suggests that the STAT3/NFAT axis is a promising therapeutic target in PAH. Although plumbagin restored bone morphogenetic protein receptor type 2 expression that had been down-regulated by MCT, molecular hydrogen showed a nonsignificant tendency toward restoration. In addition, expressions of TGFBRs and Smads showed no significant differences between groups in our study.

In terms of clinical application, molecular hydrogen offers advantages from the perspective of toxicity. Hydrogen has already been used in humans to prevent high-pressure nervous syndromes in deep sea divers. ${ }^{7}$ In addition, safety standards have been established for hydrogen inhalation to help prevent decompression sickness and arterial gas thrombi. ${ }^{34}$ Reports of adverse effects from the use of hydrogen are limited, but hypoglycemia was described in a patient who had insulintreated mitochondrial myopathy with lactic acidosis and stroke-like episodes. ${ }^{35}$

Although our model does not cover all types of PAH, molecular hydrogen may be applicable for patients who have PAH associated with connective tissue disease, PAH associated with infection, or idiopathic PAH. In addition, ischemia-reperfusion-induced lung injury accompanying cardiopulmonary bypass is, at least in part, attributable to oxidative stress. As a result, molecular hydrogen may be applicable to patients with $\mathrm{PAH}$ on cardiopulmonary bypass.

To date, molecular hydrogen has been administered in several ways, including inhalation of hydrogen gas, ingestion by drinking hydrogen-rich water, and intravenous or intraperitoneal injection of hydrogen-rich saline, in various disease models. ${ }^{34}$ For a rat model of pulmonary hypertension, oral administration and intraperitoneal injection of molecular hydrogen have similar effects. ${ }^{29}$ In line with that study, our study demonstrated that oral administration of molecular hydrogen was effective in our protocol. Current drugs for pulmonary hypertension include inhalants, injections, and oral medicines. However, frequent inhalation or continuous intravenous administration requires more effort for patients. In contrast, the oral intake of hydrogen-rich water may be more convenient for patients.

Beneficial effects of molecular hydrogen have been explained by several mechanisms, including specific scavenging of peroxynitrite or hydroxyl radicals, the strongest of the oxidative species, or regulation of gene expression and modulation of signaling. ${ }^{7}$ Although our study demonstrated beneficial effects of molecular hydrogen, in inhibiting PAH, with regulation of monocyte 
chemoattractant protein-1 and stromal cell-derived factor-1 expression, and modulation of the STAT3/NFAT axis, the direct target of molecular hydrogen remains unknown. To clarify the mechanisms and promote effective utilization of molecular hydrogen, identification of a direct target is required, to illuminate the modulation of cytokines and the signaling pathways involved in these mechanisms. Downstream components of this target may be additional potential therapeutic targets for PAH.

\section{Limitations}

The MCT model is commonly used and displays increased apoptosis of endothelial cells, proliferation of pulmonary arterial smooth muscle cells, and resistance of pulmonary arterial smooth muscle cells to apoptosis and the contribution of inflammatory cells, thus sharing characteristics of human idiopathic PAH. In addition, this model shows advantages in terms of reproducibility and cost. Drawbacks of this model include the fact that MCT-induced PAH is a single-hit model, whereas PAH in humans is considered to develop by multiple hits. In addition, this model does not mimic severe forms of PAH with intimal hyperplasia or plexiform lesions. The lack of evaluation using other models of $\mathrm{PAH}$, such as hypoxia-induced PAH or Sugen-hypoxia-induced PAH, thus represents a substantial limitation to this study.

\section{Conflict of Interest Statement}

Authors have nothing to disclose with regard to commercial support.

The authors acknowledge the Division for Medical Research Engineering, Nagoya University Graduate School of Medicine. The authors thank Miz Company for providing the AquelaBlue and Ms Saori Inoguchi for technical assistance.

\section{References}

1. Benza RL, Miller DP, Barst RJ, Badesch DB, Frost AE, McGoon MD. An evaluation of long-term survival from time of diagnosis in pulmonary arterial hypertension from the REVEAL Registry. Chest. 2012;142:448-56.

2. Barst RJ, McGoon MD, Elliott CG, Foreman AJ, Miller DP, Ivy DD. Survival in childhood pulmonary arterial hypertension: insights from the registry to evaluate early and long-term pulmonary arterial hypertension disease management. Circulation. 2012;125:113-22.

3. Perez-Vizcaino F, Cogolludo A, Moreno L. Reactive oxygen species signaling in pulmonary vascular smooth muscle. Respir Physiol Neurobiol. 2010;174: 212-20.

4. Price LC, Wort SJ, Perros F, Dorfmuller P, Huertas A, Montani D, et al. Inflammation in pulmonary arterial hypertension. Chest. 2012;141:210-21.

5. Ohsawa I, Ishikawa M, Takahashi K, Watanabe M, Nishimaki K, Yamagata K, et al. Hydrogen acts as a therapeutic antioxidant by selectively reducing cytotoxic oxygen radicals. Nat Med. 2007;13:688-94.

6. Fu Y, Ito M, Fujita Y, Ichihara M, Masuda A, Suzuki Y, et al. Molecular hydrogen is protective against 6-hydroxydopamine-induced nigrostriatal degeneration in a rat model of Parkinson's disease. Neurosci Lett. 2009;453: $81-5$.

7. Ohno K, Ito M, Ichihara M. Molecular hydrogen as an emerging therapeutic medical gas for neurodegenerative and other diseases. Oxid Med Cell Longev. 2012;2012:353152.
8. Paulin R, Courboulin A, Meloche J, Mainguy V, Dumas de la Roque E, Saksouk N, et al. Signal transducers and activators of transcription-3/pim1 axis plays a critical role in the pathogenesis of human pulmonary arterial hypertension. Circulation. 2011;123:1205-15.

9. Ramiro-Diaz JM, Nitta CH, Maston LD, Codianni S, Giermakowska W, Resta TC, et al. NFAT is required for spontaneous pulmonary hypertension in superoxide dismutase 1 knockout mice. Am J Physiol Lung Cell Mol Physiol. 2013;304:L613-25.

10. Dumitrascu R, Kulcke C, Konigshoff M, Kouri F, Yang X, Morrell N, et al Terguride ameliorates monocrotaline-induced pulmonary hypertension in rats. Eur Respir J. 2011;37:1104-18.

11. Ito M, Hirayama M, Yamai K, Goto S, Ichihara M, Ohno K. Drinking hydrogen water and intermittent hydrogen gas exposure, but not lactulose or continuous hydrogen gas exposure, prevent 6-hydroxydopamine-induced Parkinson's disease in rats. Med Gas Res. 2012;2:15.

12. Fagan KA, Oka M, Bauer NR, Gebb SA, Ivy DD, Morris KG, et al. Attenuation of acute hypoxic pulmonary vasoconstriction and hypoxic pulmonary hypertension in mice by inhibition of Rho-kinase. Am J Physiol Lung Cell Mol Physiol. 2004; 287:L656-64.

13. Mitani Y, Maruyama J, Jiang BH, Sawada H, Shimpo H, Imanaka-Yoshida K, et al. Atrial natriuretic peptide gene transfection with a novel envelope vector system ameliorates pulmonary hypertension in rats. J Thorac Cardiovasc Surg. 2008; 136:142-9.

14. Beppu H, Ichinose F, Kawai N, Jones RC, Yu PB, Zapol WM, et al. BMPR-I heterozygous mice have mild pulmonary hypertension and an impaired pulmonary vascular remodeling response to prolonged hypoxia. Am J Physiol Lung Cell Mol Physiol. 2004;287:L1241-7.

15. Soon E, Holmes AM, Treacy CM, Doughty NJ, Southgate L, Machado RD, et al Elevated levels of inflammatory cytokines predict survival in idiopathic and familial pulmonary arterial hypertension. Circulation. 2010;122:920-7.

16. Quarck R, Nawrot T, Meyns B, Delcroix M. C-reactive protein: a new predictor of adverse outcome in pulmonary arterial hypertension. J Am Coll Cardiol. 2009; 53:1211-8.

17. Tuder RM, Groves B, Badesch DB, Voelkel NF. Exuberant endothelial cell growth and elements of inflammation are present in plexiform lesions of pulmonary hypertension. Am J Pathol. 1994;144:275-85.

18. Dorfmuller P, Humbert M, Perros F, Sanchez O, Simonneau G, Muller KM, et al Fibrous remodeling of the pulmonary venous system in pulmonary arteria hypertension associated with connective tissue diseases. Hum Pathol. 2007;38: 893-902.

19. Sahara M, Sata M, Morita T, Nakamura K, Hirata Y, Nagai R. Diverse contribution of bone marrow-derived cells to vascular remodeling associated with pulmonary arterial hypertension and arterial neointimal formation. Circulation. 2007;115:509-17.

20. Frid MG, Brunetti JA, Burke DL, Carpenter TC, Davie NJ, Reeves JT, et al Hypoxia-induced pulmonary vascular remodeling requires recruitment of circulating mesenchymal precursors of a monocyte/macrophage lineage. Am J Pathol. 2006;168:659-69.

21. Price LC, Montani D, Tcherakian C, Dorfmuller P, Souza R, Gambaryan N, et al Dexamethasone reverses monocrotaline-induced pulmonary arterial hypertension in rats. Eur Respir J. 2011;37:813-22.

22. Tanaka E, Harigai M, Tanaka M, Kawaguchi Y, Hara M, Kamatani N Pulmonary hypertension in systemic lupus erythematosus: evaluation of clinical characteristics and response to immunosuppressive treatment. J Rheumatol. 2002;29:282-7.

23. Schober A. Chemokines in vascular dysfunction and remodeling. Arterioscle Thromb Vasc Biol. 2008;28:1950-9.

24. Olive M, Mellad JA, Beltran LE, Ma M, Cimato T, Noguchi AC, et al p21Cip1 modulates arterial wound repair through the stromal cell-derived factor-1/CXCR4 axis in mice. J Clin Invest. 2008;118:2050-61.

25. Schober A, Zernecke A. Chemokines in vascular remodeling. Thromb Haemost 2007; $97: 730-7$.

26. Bowers R, Cool C, Murphy RC, Tuder RM, Hopken MW, Flores SC, et al. Oxidative stress in severe pulmonary hypertension. Am J Respir Crit Care Med. 2004;169:764-9.

27. Csiszar A, Labinskyy N, Olson S, Pinto JT, Gupte S, Wu JM, et al. Resveratro prevents monocrotaline-induced pulmonary hypertension in rats. Hypertension 2009;54:668-75.

28. Wang Y, Jing L, Zhao XM, Han JJ, Xia ZL, Qin SC, et al. Protective effects of hydrogen-rich saline on monocrotaline-induced pulmonary hypertension in a rat model. Respir Res. 2011;12:26. 
29. He B, Zhang Y, Kang B, Xiao J, Xie B, Wang Z. Protection of oral hydrogen water as an antioxidant on pulmonary hypertension. Mol Biol Rep. 2013;40: $5513-21$.

30. Bonnet S, Rochefort G, Sutendra G, Archer SL, Haromy A, Webster L, et al. The nuclear factor of activated $\mathrm{T}$ cells in pulmonary arterial hypertension can be therapeutically targeted. Proc Natl Acad Sci U S A. 2007;104:11418-23.

31. Li FY, Zhu SX, Wang ZP, Wang H, Zhao Y, Chen GP. Consumption of hydrogen-rich water protects against ferric nitrilotriacetate-induced nephrotoxicity and early tumor promotional events in rats. Food Chem Toxicol. 2013;61:248-54.

32. Hamidi SA, Lin RZ, Szema AM, Lyubsky S, Jiang YP, Said SI. VIP and endothelin receptor antagonist: an effective combination against experimental pulmonary arterial hypertension. Respir Res. 2011;12:141.
33. Courboulin A, Barrier M, Perreault T, Bonnet P, Tremblay VL, Paulin R, et al Plumbagin reverses proliferation and resistance to apoptosis in experimental PAH. Eur Respir J. 2012;40:618-29.

34. Ohta S. Molecular hydrogen as a preventive and therapeutic medical gas: initiation, development and potential of hydrogen medicine. Pharmacol Ther. 2014;144:1-11.

35. Ito M, Ibi $\mathrm{T}$, Sahashi $\mathrm{K}$, Ichihara $\mathrm{M}$, Ohno $\mathrm{K}$. Open-label trial and randomized, double-blind, placebo-controlled, crossover trial of hydrogenenriched water for mitochondrial and inflammatory myopathies. Med Gas Res. 2011;1:24.

Key Words: pulmonary arterial hypertension, molecular hydrogen, NFAT, STAT3, reactive oxygen species

\title{
EDITORIAL COMMENTARY
}

\section{Molecular hydrogen: A novel therapy for the treatment of pulmonary hypertension}

\author{
Harold L. Lazar, MD
}

See related article on pages 645-54.

Patients with pulmonary arterial hypertension $(\mathrm{PAH})$ are at higher risk for morbidity and mortality after all types of cardiac surgical procedures. These patients have higher incidences of hemodynamic instability, hypoxemia, and right ventricular dysfunction. Current therapy for PAH has included prostanoids, endothelial receptor antagonists, and phosphodiesterase inhibitors. Although these agents have helped to improve oxygenation and hemodynamics in the postoperative period, PAH is still associated with poor surgical outcomes.

In their study in this issue of the Journal, Kishimoto and coworkers ${ }^{1}$ have demonstrated that molecular hydrogen can decrease monocrotaline-induced PAH in a rat model by suppressing macrophage accumulation, reducing oxidative stress, and modulating the STAT3/NFAT axis. The pathogenesis of PAH involves both reactive oxygen

From the Department of Cardiothoracic Surgery, Boston Medical Center, Boston, Mass.

Disclosures: Author has nothing to disclose with regard to commercial support.

Received for publication June 3, 2015; accepted for publication June 3, 2015; available ahead of print June 27, 2015.

Address for reprints: Harold L. Lazar, MD, Department of Cardiothoracic Surgery, Boston Medical Center, 88 E Newton St, Suite B 404, Boston, MA 02118 (E-mail: Harold.lazar@bmc.org).

J Thorac Cardiovasc Surg 2015;150:654-5

$0022-5223 / \$ 36.00$

Copyright (c) 2015 by The American Association for Thoracic Surgery

http://dx.doi.org/10.1016/j.jtcvs.2015.06.004 species and inflammation. Molecular hydrogen has both anti-inflammatory and antioxidative activities.

In this study, PAH was induced by injecting rats with monocrotaline. In the group treated with oral molecular hydrogen, PAH decreased right ventricular systolic pressure, reduced the percentage of muscularized pulmonary arteries, and inhibited smooth muscle proliferation and vascular remodeling after 16 days.

Molecular hydrogen represents a new and potentially effective therapy for the treatment of PAH. Several questions remain to be addressed, however, before this novel therapy can be introduced into the practice of clinical cardiac surgery. The studies of Kishimoto and coworkers ${ }^{1}$ were performed in a rat model in which PAH was induced by monocrotaline treatment. Is this type of PAH sufficiently similar to that seen in cardiac surgery, where the etiology of PAH is due to long-standing pressure and volume overload from valvular and coronary disease or idiopathic etiologies? PAH was present for only 16 days in this model, and oral hydrogen therapy was initiated concomitantly with monocrotaline. Will hydrogen therapy be equally effective in patients with long-standing PAH? During cardiac surgery, reducing PAH is important for weaning from cardiopulmonary bypass. Will an inhaled form of molecular hydrogen be equally effective in reducing $\mathrm{PAH}$ intraoperatively, to allow earlier weaning from cardiopulmonary bypass and for therapy in the early postoperative period? 
Group C
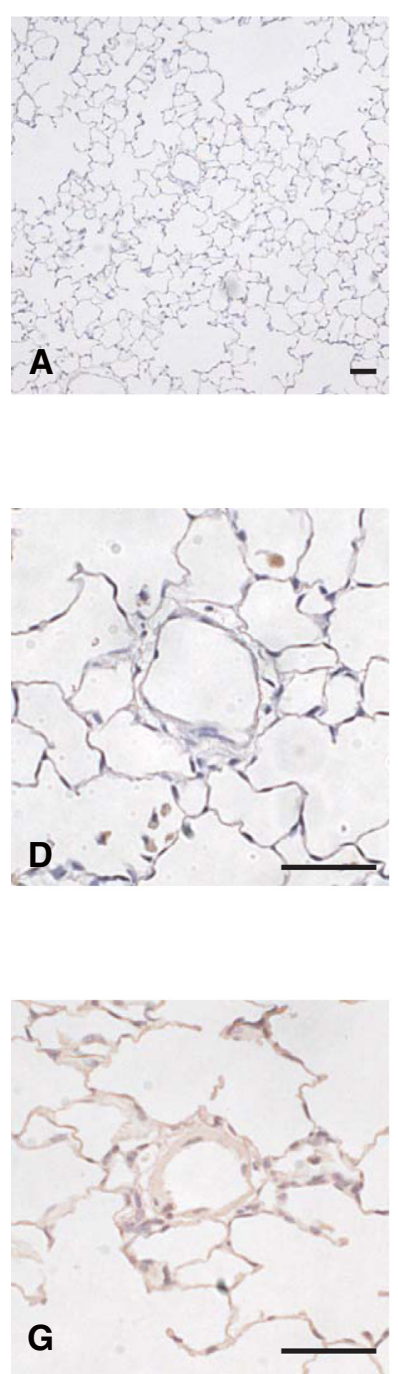

Group M
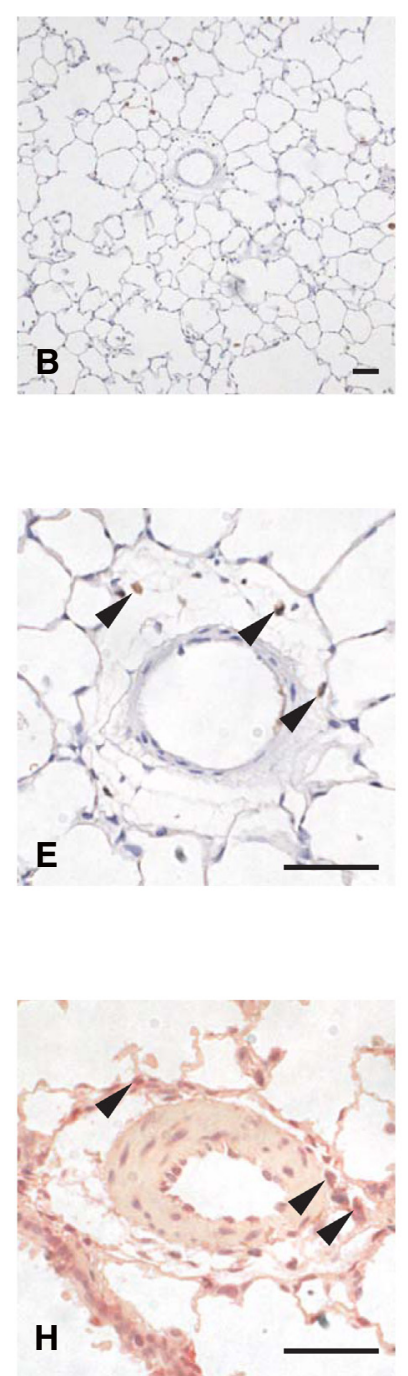

Group H
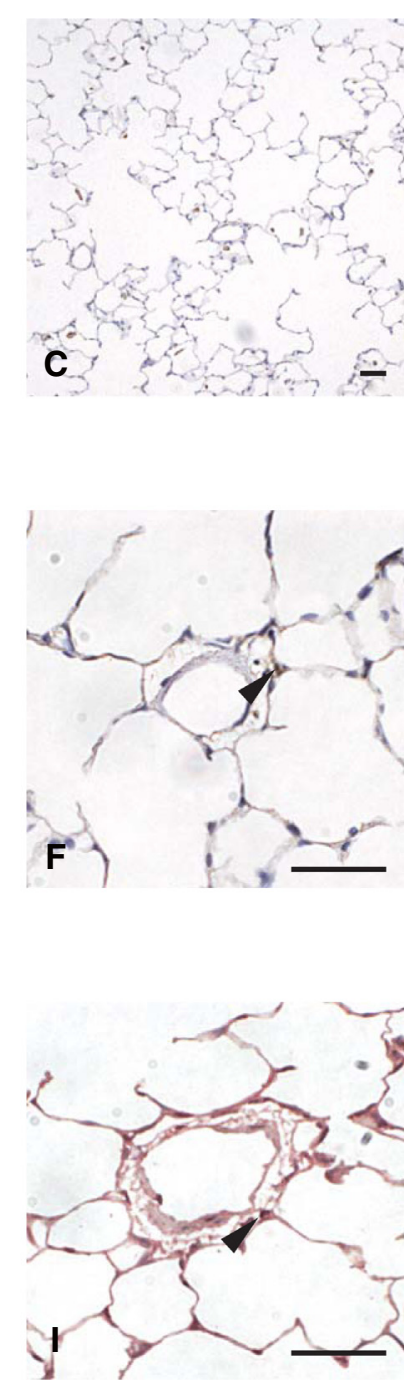

FIGURE E1. Molecular hydrogen reduces adventitial CD68- and 8-OHdG-positive cells on immunohistochemistry. A-F (arrowheads), CD68-positive cells, and (G-I, arrowheads) 8-OHdG-positive cells are increased by MCT, but decreased by molecular hydrogen. Scale bar $=50 \mu \mathrm{m}$. 

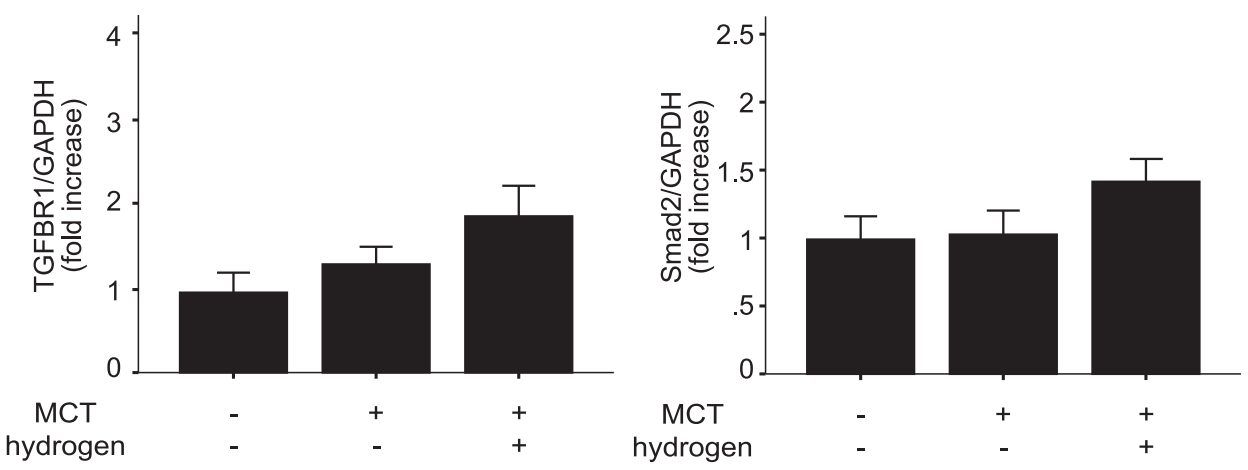

A

D
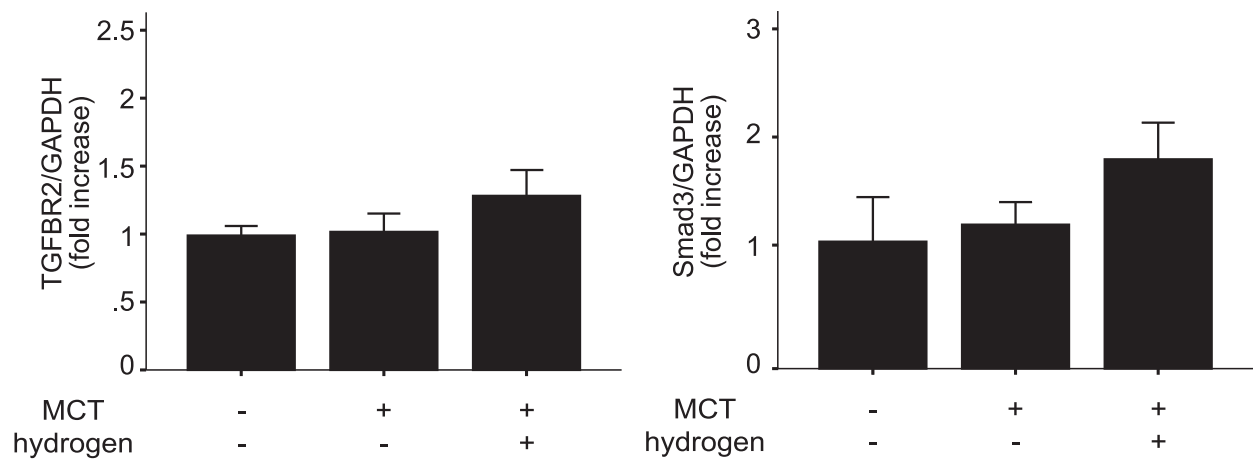

B

E
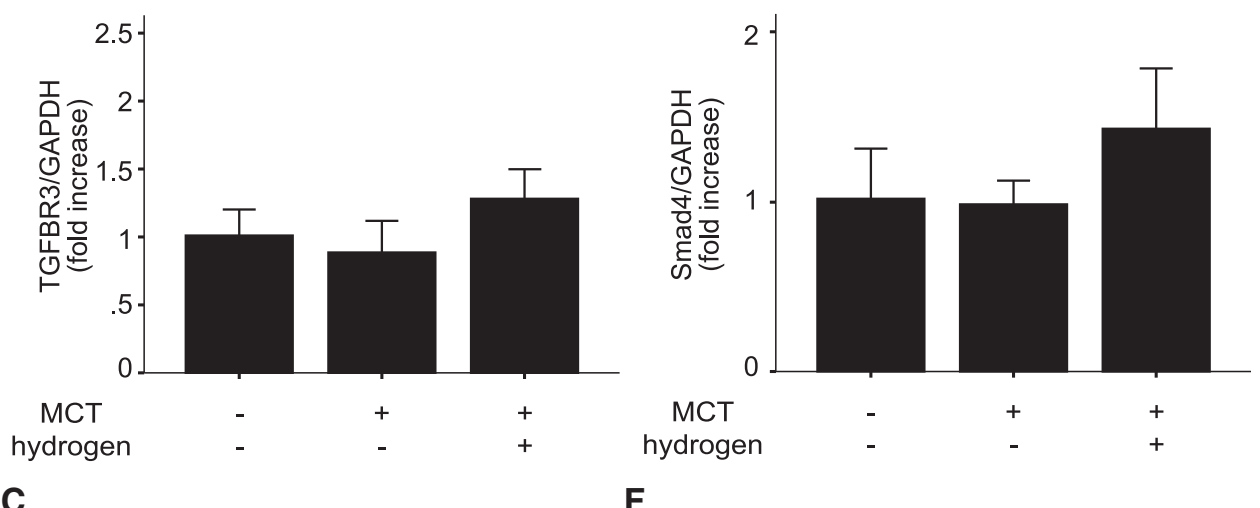

$\mathbf{F}$

FIGURE E2. Expressions of TGFBR1, TGFBR2, TGFBR3, Smad2, Smad3, and Smad4, as evaluated by quantitative reverse-transcription polymerase chain reaction, showed no significant change among the 3 groups. TGFBR, Transforming growth factor beta receptor; GAPDH, glyceraldehyde 3-phosphate dehydrogenase; $M C T$, monocrotaline. 
TABLE E1. Primers employed for reverse-transcription polymerase chain reaction

\begin{tabular}{|c|c|c|}
\hline Genes & Forward primer & Reverse primer \\
\hline SDF-1 & $5^{\prime}$-TGAGAGCCATGTCGCCAGA-3' & $5^{\prime}$-GGATCCACTTTAATTTCGGGTCAA-3' \\
\hline MCP-1 & 5'-CTATGCAGGTCTCTGTCACGCTTC-3' & $5^{\prime}$-CAGCCGACTCATTGGGATCA-3' \\
\hline BMPR2 & 5'-TGTTACAAGCACAGCTGCACC-3' & 5'-GATTTGCCATCCTGCGTTGAC-3' \\
\hline TGFBR1 & $5^{\prime}$-CACACAGTCAGTGCGGTGAGAG-3' & $5^{\prime}$-AGAGGCCCACAAGAGTTTCAACA- $3^{\prime}$ \\
\hline TGFBR2 & 5'-GCGATCTAACCTGTTGCCTGTG-3' & 5'-GGGCCATGTATCTCGCTGTTC-3' \\
\hline TGFBR3 & 5'-ACAATGGCTCCCGTGGCTAA-3' & $5^{\prime}$-CAGGGTCCAGCAGGATACGAA-3' \\
\hline Smad2 & $5^{\prime}$-TTACAGATCCATCGAACTCGGAGA-3' & 5'-CACTTAGGCACTCGGCAAACAC-3' \\
\hline Smad3 & 5'-GCACAGCAAGTTCCCAGTGTGTA-3' & 5'-GCCATGCATCCACATGTTCC-3' \\
\hline Smad4 & $5^{\prime}$-CAGCACTACCACCTGGACTGGA-3' & 5'-CTGGAATGCAAGCTCATTGTGAA-3' \\
\hline GAPDH & $5^{\prime}$-GGCACAGTCAAGGCTGAGAATG-3' & 5'-ATGGTGGTGAAGACGCCAGTA-3' \\
\hline
\end{tabular}

